\title{
Soluções tecnológicas ecoeficientes para o desenvolvimento sustentável: uma análise teórico-conceitual
}

\author{
Soluções tecnológicas ecoeficientes para o desenvolvimento sustentável: uma análise teórico-conceitual
}

\author{
Luiz Alberto Leandro', Elza Maria Neffa ${ }^{2}$ \\ 1,2 Universidade Federal Rural do Rio de Janeiro
}

\section{Resumo}

A problemática em torno da questão ambiental perpassa pelo sentido de qualidade de vida e bem estar das nações que parece, estar associado ao crescimento econômico e ao consumo. A questão socioambiental é uma dimensão do desenvolvimento e deve ser considerada em todos os níveis de tomada de decisão na arena política. Este trabalho traz a reflexão acerca da questão do desenvolvimento sustentável e das contradições presentes no apontamento de soluções puramente tecnológicas como estratégias para superação da crise ambiental. Como alternativa às soluções puramente tecnológicas emerge o conceito de ecodesenvolvimento, como uma maneira de escapar do modelo de desenvolvimento que utiliza o crescimento econômico, basicamente, como única medida de eficiência. Acreditamos, que a gestão ambiental comprometida com o planejamento público orientado para um ideal emancipador é capaz de contribuir para a construção de sociedades sustentáveis. Mesmo que se trabalhe a ecoeficiência, a modernização ecológica, o desenvolvimento sustentável e a economia verde, tais técnicas, por si só, parecem não apresentar soluções efetivas que gerem um tipo de desenvolvimento que consiga promover mudanças estruturais no sistema em termos de políticas públicas e de novas formas de compreender e lidar com a temática do crescimento econômico.

Palavras-chave: desenvolvimento, tecnologia, economia verde, gestão ambiental.

\begin{abstract}
The environmental issue involves the meaning of quality of life and well- being of nations that seem to be associated with economic growth and consumption. The environmental issue is a development dimension and should be considered at all levels of decision making in the political scenario. This paper presents a reflection on the issue of sustainable development and the contradictions present in the indication of purely technological solutions as strategies for overcoming the environmental crisis. As an alternative to purely technological solutions the concept of eco-development arises, as a way out of the development model that uses economic growth basically as a single measure of efficiency. We believe that environmental management committed to public planning oriented towards an emancipatory ideal is able to contribute to building sustainable societies. Even if we develop eco-efficiency, ecological modernization, sustainable development and the green economy, such techniques alone do not seem to provide effective solutions that generate a type of development that can promote structural changes in the system in terms of public policies and new ways of understanding and dealing with the theme of economic growth.
\end{abstract}

Keywords: development, technology, green economy, environmental management 


\section{INTRODUÇÃO}

Esse texto tem como objetivo realizar uma breve reflexão acerca da questão do desenvolvimento sustentável e das contradições presentes no apontamento de soluções puramente tecnológicas como estratégias para superação da crise ambiental vigente. Para tal, recorremos a literatura contemporânea que trata dessa temática.

Os estudos acerca da crise ambiental vêm ocorrendo institucionalmente desde as décadas de 60 e 70 (Estocolmo, Clube de Roma, Conferência para a Conservação da Natureza etc.) e a questão do desenvolvimento sustentável foi enfatizada na publicação do Relatório Nosso Futuro Comum na segunda metade dos anos 80 (WCED, 1987). A despeito de todos esses esforços observa-se a insistente tentativa de conciliação entre crescimento econômico e sustentabilidade socioambiental (MÉSZÁROS, 2011a; 2011b; VEIGA, 2010; MARTÍNEZ-ALIER, 2007; SACHS, 2007; CARNEIRO, 2005; SILVA et al., 2005; LEFF, 2002; LITTLE, 2001; ACSELRAD, 1999).

A problemática em torno da questão ambiental perpassa pelo sentido de qualidade de vida e bem estar das nações que parece, na maioria dos casos, estar associado ao crescimento econômico e ao consumo, fato que autores como Kallis et al (2012) e Victor (2008) afirmam ser controverso tendo em vista que o crescimento econômico, para atender à demanda do capitalismo contemporâneo, em uma perspectiva global, causa mais custos do que benefícios, especialmente do ponto de vista socioambiental. Concordando com Kallis et al. (2012), Hoepner et al. (2012) e Klitgaard e Krall (2011) consideramos que as preocupações das nações, especialmente das que apresentam elevado potencial de crescimento econômico, como o Brasil, não deveriam estar orientadas para o enriquecimento (e para indicadores de crescimento como o PIB, no caso brasileiro), mas para o gerenciamento de suas potencialidades, de forma a constituir um modelo de desenvolvimento sem que o crescimento da produtividade industrial seja considerado o principal paradigma de gestão. Algumas soluções apresentadas por empresas e governo parecem apontar para tecnologias que buscam encontrar formas de atingir o progresso material conciliando crescimento com conservação e preservação ambiental através da aplicação de técnicas que, em muitos casos, não levam em consideração o meio ambiente sendo composto por três elementos interrelacionados: o meio físico-natural em si, as estruturas construídas pelo homem e o meio social (SACHS, 2007; LEIS, 1994). Todavia, autores como Guimarães e Tomazello (2003) e Sachs (2007) afirmam que além da tecnologia, são necessárias ações socioeducativas que proporcionem mudanças de hábitos, valores e atitudes.

\section{A QUESTÃO DO DESENVOLVIMENTO NO BRASIL}

O Brasil é o maior país do continente sul-americano, dadas as suas dimensões continentais $8.514 .876,599 \mathrm{~km}^{2}$; quarto maior do mundo se consideradas terras contínuas, e quinto, considerando-se terras descontínuas (IBGE, 2010). Detentor de uma das maiores biodiversidades do planeta ocupa a lista dos 18 países megadiversos que concentram $70 \%$ das espécies animais e vegetais do mundo. Possuidor de cerca de $10 \%$ das espécies do planeta, $14 \%$ da água potável renovável, é considerado um verdadeiro celeiro para a produção de alimentos, com estoques amplos de carbono florestal (SCARANO et al, 2010). Tais dados colocam o país no topo das nações com maior abundância de diversidade e recursos naturais $^{1}$ que, em tese, seria capaz de contribuir para o seu desenvolvimento. Entretanto, uma análise mais acurada permite entrever que a problemática ambiental no Brasil, desde a instituição do Decreto Federal 23.793/34, o meio ambiente é, muitas vezes, concebido como elemento para a reprodução da lógica de produção.

As discussões acerca da gestão ambiental aprofundaram-se, no Brasil, na década de 1970, emergindo como um tipo de resposta à crise ambiental internacional que se instalava e, também, como uma espécie de retorno à pressão feita pelos países industrializados logo após a Conferência de Estocolmo

\footnotetext{
1 Observamos que apesar de recursos naturais ser uma expressão bastante criticada entre por autores, porque trata a natureza de forma reduzida, como simples fonte de riqueza, concordamos com Sachs (2007) que apresenta a noção como o conjunto de todos os bens presentes no meio natural que são utilizados (e na maioria das vezes transformados) pelo ser humano para promover a manutenção e reprodução de sua existência. A existência humana depende da utilização dos bens naturais (de uso comum), que são recursos para a manutenção da vida. Ressalte-se que essa noção possui também uma dimensão cultural, pois correspondem a estimativas das sociedades sobre o seu meio. Logo, justificamos a utilização da expressão no presente texto por possuir para nós um sentido mais abrangente do que o comumente utilizado.
} 
em $1972^{2}$ (SANTOS, 2004; LIMA, 2011). Embora o debate tenha sido iniciado por conta dos limites impostos à produção industrial dos países do Hemisfério Norte, a institucionalização da temática na agenda política brasileira ensejou, nos anos 70 , avanços importantes no âmbito da legislação ambiental brasileira. Mesmo com os avanços promovidos no arcabouço legal, o Brasil enfrenta ainda a contradição presente na tentativa de conciliação entre crescimento econômico e desenvolvimento socioambiental.

Segundo a Organização Mundial do Comércio (WTC, 2010), o Brasil é o terceiro maior exportador de produtos agropecuários do mundo, tendo apresentado um crescimento de $18 \%$ das exportações de commodities ${ }^{3}$ na década passada. Embora os números sejam elevados, a desigualdade social no campo é acentuada, pois $16 \%$ dos estabelecimentos rurais que incorporam o agronegócio não familiar às suas atividades produtivas ocupam $86 \%$ das terras cultiváveis do país. O tamanho médio das terras ocupadas pelos agronegócios é 16 vezes maior que a média das terras utilizadas pelo agricultor familiar. Uma economia como a brasileira não poderia apoiar seu crescimento em vantagens comparativas, exportação de commodities, com efeitos limitados sobre emprego e renda, pois tal política acentua ainda mais a problemática das vulnerabilidades sociais e ambientais observadas a partir da ótica do desenvolvimento socioambiental.

\section{O DESENVOLVIMENTO SUSTENTÁVEL E SUAS CONTRADIÇÕES}

A noção inicial de Desenvolvimento Sustentável pôde ser observada na década de 70, juntamente com as primeiras conferências internacionais sobre o meio ambiente. Porém, o tema foi aprofundado a partir dos anos 80, mais especificamente com a elaboração do Relatório Nosso Futuro Comum (WECD, 1987), onde foi definido como um tipo de desenvolvimento que deve atender às necessidades atuais sem comprometer as demandas das futuras gerações. Embora o conceito de Desenvolvimento Sustentável tenha sido bastante debatido durante a Rio-92, autores como Veiga (2010), Sachs (2007) e Freitas (2004) afirmam que o conceito desenvolvimento é carregado de contradições e ambiguidades tendo sido tratado, durante todo o século XX, como sinônimo de crescimento econômico.

A ambiguidade da noção de desenvolvimento sustentável reside em que ao mesmo tempo que se aceita a existência de limites aos modos de vida que não sejam compatíveis com os princípios ecológicos, mantém-se a crença no crescimento ou desenvolvimento [...] para satisfazer as necessidades humanas. A ela junta-se a indefinição do conceito de necessidade (GARCIA; VERGARA, 2000 apud FREITAS, 2004, p. 549).

Embora o slogan desenvolvimento sustentável esteja presente no discurso dos Estados e das grandes empresas transnacionais, poucos de nós refletimos a respeito das bases epistemológicas deste modelo de desenvolvimento proposto pelas nações ditas desenvolvidas. A Conferência das Nações Unidas sobre o Desenvolvimento Humano e o Meio Ambiente, realizada no Rio de Janeiro em 1992 (Rio-92) enfatizou a questão da informação e do acesso a tecnologias como essenciais para o alcance do Desenvolvimento Sustentável. Cabe aqui, antes de seguirmos adiante nas reflexões acerca do conceito de desenvolvimento sustentável, falarmos sobre o termo sustentabilidade. O adjetivo sustentável apresenta a ideia de algo passível de sustentação, ou seja, alguma coisa que traz em si constância, perenidade e regularidade. O professor José Eli da Veiga (2010) fez uma completa explanação sobre o termo no capítulo 3 de seu livro Desenvolvimento sustentável: o desafio para o século XXI. Segundo ele, a literatura dedicada ao tema apresenta basicamente três caminhos para a compreensão da sustentabilidade, onde dois entendimentos são mutuamente excludentes (contrários) e um terceiro busca uma via intermediária para tratar do assunto. É importante ressaltar que esse último está no campo do que Veiga (2010, p. 109) chama de "retórica político-ideológica", ainda pouco clara na maior parte da literatura, onde autores como Ignacy Sachs (2007) desenvolvem trabalhos consistentes. Neste texto,

\footnotetext{
2 Primeira conferência Mundial do Meio Ambiente Humano foi considerada como um dos marcos históricos para as discussões acerca da problemática ambiental. Tal conferência reuniu representantes de 113 países que tinham como meta o estabelecimento de uma visão global e princípios comuns que servissem para orientar o mundo no sentido de preservar e melhorar o ambiente humano (TOZONI-REIS, 2004). 3 É um termo proveniente da língua inglesa que é utilizado para designar produtos (bens serviços) não diferenciados pois são habitualmente substâncias extraídas da terra e que mantém até certo ponto um preço universal.
} 
trataremos os termos sustentabilidade e sustentável como sinônimos, assim como temos observado na literatura corrente sobre o tema.

A primeira teoria em torno da sustentabilidade é baseada na curva ambiental de Kuznets ${ }^{4}$ e traz a hipótese de que o crescimento econômico, causado pela industrialização e uso dos recursos naturais, traria danos ao meio ambiente até determinado ponto. De acordo com essa teoria, quando a riqueza aferida pelo PIB da nação chegar a um determinado patamar a tendência será inversa, ou seja, o crescimento econômico fará com que a qualidade ambiental seja aumentada por meio do investimento em tecnologias capazes de combater a poluição trazendo mais eficiência produtiva para os insumos, produzindo, inclusive, maior lucratividade por conta da reutilização do material que seria considerado sucata ou poluente (PORTER; VAN DER LINDE, 1998). Embora tal teoria seja bastante defendida e difundida entre os adeptos desse modelo de desenvolvimento ${ }^{5}$, estudos realizados na cena nacional e internacional apontam para a fragilidade de tal hipótese, pois as nações possuem variáveis que são essencialmente diferentes e mais complexas do que as utilizadas para compor a equação de Kuznets, fazendo com que a teoria se perca em sua metodologia reduzida e linear (BROCK; TAYLOR, 2004; DASGUPTA et al, 2002; ARRAES et al, 2006). Talvez, metodologicamente, essa teoria até se aplique em análises isoladas. Porém, pensando na totalidade das diferentes nações e em seus direitos de avançarem no processo de desenvolvimento para chegar até ao ponto da curva em que a degradação recue, o problema ambiental já seria crônico, pois os países desenvolvidos continuariam com seus estilos de vida, gerando poluição a partir da pressão sobre o consumo e, assim, quando essa nação em desenvolvimento atingisse o ponto de Kuznets, o problema estaria agravado em termos de seus efeitos globais. Embora as críticas a essa teoria se acumulem, Veiga (2010) relata que diversos periódicos internacionais ainda investem em publicações que busquem justificá-la o que, ideologicamente, faz com que a mesma ainda possua bastante relevância nas perspectivas econômicas da crise ambiental.

A segunda vertente de análise do conceito de sustentabilidade parte do princípio de que, na prática, a sustentabilidade absoluta dos sistemas produtivos seria uma falácia, pois contraria a Lei da Entropia que traz o postulado de que:

toda transformação energética envolve produção de calor. Ele tende a se dissipar, e por isso é a forma mais degradada de energia. Embora uma parte possa ser recuperada para algum propósito útil, não se pode aproveitar todo o calor. Justamente devido a sua tendência a se dissipar. Assim, a essência da Lei da Entropia é que a degradação da energia tende a um máximo em um sistema isolado, e que tal processo é irreversível. Claro, sistemas que conseguem manter um padrão de organização, como as mais diversas formas de vida, não são isolados. São abertos e existem em áreas de fluxo energético. Sistemas isolados não trocam nem matéria nem energia com o meio. Os sistemas abertos trocam tanto energia quanto matéria. E "fechados" são aqueles que trocam apenas energia. O planeta Terra é fechado, pois a quantidade de materiais não muda mesmo recebendo permanentemente o indispensável fluxo de energia do sol (SCHNEIDER; SAGAN, 2005 apud CHECHIN; VEIGA, 2010).

Ora, como manter o desenvolvimento sem que a lógica do crescimento constante seja alterada? A tese de Georgescu (1986) baseia-se na hipótese de que o modo de produção fundamentado no modelo capitalista de competição e crescimento exponencial pressupõe que o sistema econômico é fechado e circular, onde a produção e o consumo seriam permanentes e tenderiam ao infinito, trazendo a ideia de um motor-perpétuo, conceito que claramente contraria a Lei da Entropia (CHECHIN; VEIGA, 2010), fazendo com que seja impossível pensar em um modelo econômico que pregue o crescimento contínuo e autossustentado. Para Georgescu (1971, apud Veiga, 2010), é necessária a interação com o meio físico natural para que ocorra a manutenção e a reprodução do sistema. Uma vez que há escassez, esgotamento de insumos ou de energia, provenientes do meio, o sistema tende a entrar em colapso. Para esse autor, a humanidade deveria então reduzir drasticamente os níveis de produção e consumo

4 Baseada nas pesquisas desenvolvidas nos anos 50, pelo ganhador do prêmio Nobel de Economia (1971) Simon Kuznets. Na forma de um U invertido, a Curva Ambiental de Kuznets (CAK) representa a relação entre renda per capita e degradação ambiental: enquanto aumenta a renda de cada cidadão de um país - em geral medida pelo Produto Interno Bruto (PIB) divido pela população -, crescem também os danos ao meio ambiente, que finalmente atingem um ápice e passam a diminuir, embora a renda continue aumentando (ARRAES et al., 2006). 5 Ver estudos desenvolvidos por Grossman e Krueger (1993; 1995). 
para diminuir a velocidade do caminho para o fatídico e inevitável fim. Como um sistema fechado, o planeta tende ao esgotamento. Partindo dessa tese, Georgescu (1973, apud Veiga 2010), chegou a afirmar que a economia necessitaria ser subsumida à ecologia, pois a termodinâmica é muito mais aplicável do que a mecânica.

Veiga (2010) apresenta a informação de que a tese que se baseia na Lei da Entropia, considerada por muitos inconveniente, encontra-se descartada pela maioria dos economistas. Todavia, alguns estudiosos, a exemplo de Herman E. Daly (1997) trabalham debruçados sobre as ideias de Georgescu $(1973 ; 1976)$ e estas estão presentes em diversos programas de pesquisas no Brasil e no mundo.

Após a exposição das duas vertentes para a compreensão do adjetivo sustentável, qual seria a via alternativa presente no campo político-ideológico? Segundo Veiga (2010), a alternativa que se apresenta não chegaria a ser considerada um caminho do meio, mas sim uma proposta menos pessimista para a tese de Georgescu $(1973 ; 1976)$, onde as Nações deveriam caminhar para uma condição econômica estacionária que, na prática, não corresponderia, segundo o autor, a um crescimento zero. Nessa economia estacionária haveria crescimento qualitativo, onde alternativas mais viáveis em termos de eficiência produtiva substituíssem as menos eficientes. A condição básica para que isso ocorra será uma mudança de paradigma, onde o desenvolvimento não seja sinônimo de crescimento econômico quantitativo.

A literatura crítica revela que, no contexto econômico-ambiental, a sustentabilidade só ganha sentido se (re)pensarmos o conceito de desenvolvimento (SACHS, 2007; VEIGA, 2010). Refletir sobre a sustentabilidade sem discutirmos sobre o que pensamos ser sustentável inviabilizará que cheguemos a uma sociedade justa e equilibrada ambientalmente.

A questão socioambiental é uma dimensão do desenvolvimento e deve ser considerada em todos os níveis de tomada de decisão na arena política. Um desenvolvimento que dê conta da problemática ambiental deve ser fundamentado na redefinição dos objetivos e modalidades de ação, aliados a uma "gestão racional do ambiente" (SACHS, 2007, p. 55). Logo, todas as questões associadas ao meio ambiente devem ser acompanhadas de mudanças profundas no cenário político-econômico-educacional.

No nosso entendimento, o desenvolvimento deve estar intrinsecamente ligado à noção de igualdade, justiça social, reconhecimento das potencialidades da população, conservação ambiental e manutenção dos espaços públicos. O desafio está lançado, a crise existe e o debate e os enfrentamentos são urgentes e necessários. As respostas são complexas e exigem uma "[...] 'agenda positiva' para estratégias de desenvolvimento, sem ceder à tentação do modelo único" (ROMANO, 2009, p. 8). O crescimento econômico, a despeito dos seus limites, mostra-se necessário como uma das ferramentas para proporcionar prosperidade material para as nações, mas não deve ser considerado como a única ou a principal medida do desenvolvimento. Ressaltamos a necessidade de refletir sobre a ordem de valores, normas e comportamentos, presentes em nossa sociedade (CASTORIADIS, 1987). Estas noções, embutidas no conceito de desenvolvimento, apresentam o que tem valor e o que não tem. Logo, é preciso levar em conta a qualidade do crescimento que está sendo usado como alavanca para o desenvolvimento e não tratá-los como sinônimos. O que está em jogo é a disputa de sentidos.

\section{O ECODESENVOLVIMENTO, AS ECOTÉCNICAS E O METABOLISMO INDUSTRIAL}

De acordo com Martínez-Alier (2007), a ecoeficiência parte do pressuposto de que o desenvolvimento humano, como sinônimo de crescimento econômico e conforto, a partir das premissas de consumo capitalista, é necessário e pode ser sustentado pela utilização de tecnologias que possibilitem o uso racional dos recursos provenientes da natureza. Observamos que os adeptos dessa corrente, embora preguem a conservação ambiental, tendem a objetivar a natureza, retirando dela os seus valores essenciais, conferindo-lhe, na maior parte das vezes, apenas um sentido utilitário, onde a preocupação, ao menos discursiva, parece ser a orientada para o manejo sustentável do meio ambiente natural como recurso para a produção. Os divulgadores da ecoeficiência acreditam que o mérito dessa corrente de ação reside no fato de buscar, através da modernização ecológica ${ }^{6}$, a conciliação entre ganhos

6 A teoria da modernização ecológica, desde os anos 80, vem defendendo um outro enfoque sobre a questão da produtividade capitalista em sua interface ambiental. A modernização ecológica percebe a inovação tecnológica como condição e não restrição para o alcance da melhoria da qualidade ambiental. Para os adeptos dessa teoria, somente com a otimização dos processos produtivos e sua reestruturação tópica e contextual seria viável uma gestão mais qualificada de recursos e crescimento econômico (ANDRADE, 2003). Discutiremos um 
econômicos e qualidade ambiental. Em nossa percepção, essa corrente é uma das mais conhecidas e trabalhadas por educadores ambientais, por ter grande visibilidade social (de uma maneira geral, a sociedade consegue ver as ações ditas educativas por meio marketing verde produzido em diversas instâncias). É possível observar a atuação da ecoeficiência através dos Sistemas de Gestão Ambiental (SGA); das certificações internacionais (p.ex. ISO $14.000^{8}$ ), das técnicas de Produção Mais Limpa (PL), das avaliações dos ciclos de vida dos produtos, da logística reversa etc.

Como alternativa às soluções puramente tecnológicas, Sachs (2007) apresenta o conceito de ecodesenvolvimento, como uma maneira de escapar do modelo de desenvolvimento que utiliza o crescimento econômico, basicamente, como única medida de eficiência. Esse conceito consiste em um estilo de desenvolvimento onde cada ecorregião busca, a partir de suas especificidades, as soluções para os seus problemas - levando em conta não somente os dados ecológicos, mas, também, os socioculturais. Tudo isso relativizando e redefinindo as noções de progresso, de sustentabilidade e de desenvolvimento, não aceitando fórmulas universalistas que pretendem ser aplicadas em qualquer situação. O ecodesenvolvimento parte da observação das particularidades de cada região em matéria de população, valores, recursos, necessidades de habitação, saúde, educação e estilos de vida, onde não se buscam padrões globais hegemônicos de produção ou consumo.

Tal conceito apresenta marcadamente as dimensões discriminadas, a seguir:

1. Ecorregional: compreende o reconhecimento e a valorização dos materiais presentes na natureza (regional) que são utilizados para a satisfação das necessidades da população em termos de alimentação, moradia, lazer, educação etc. Observa-se que o conceito de necessidade deve ser (re)trabalhado por meio de processos educacionais com a finalidade de evitar o excesso de consumo, comum aos países do Norte. A observação dessa dimensão pode reduzir a pressão pelo consumo de determinadas classes de produtos e conduzir a ações preventivas, no que diz respeito ao sobreconsumo.

2. Realização humana: essa dimensão abarca todas as formas de realização, tais como, emprego, segurança, qualidade das relações humanas, respeito às diversidades, à cultura etc.

3. Solidariedade diacrônica: consiste em evitar o desperdício dos recursos naturais e maximizar a utilização dos recursos renováveis. Nesse sentido, concordamos com Sachs (2007) e Veiga (2010) ao afirmarem que a natureza, enquanto base material para a manutenção da espécie humana apresenta limites. A adoção da Ética da Responsabilidade ${ }^{9}$ (JONAS, 2006) pode

\footnotetext{
pouco mais essa questão na seção $\mathrm{X}$ desse capitulo quando tratarmos do metabolismo industrial.

7 Defende-se que termo Marketing Verde, Ecológico ou Ambiental, surgiu na década de setenta após a discussão sobre a problemática ambiental na conferencia de Estocolmo, quando a AMA (American Marketing Association) realizou uma conferência com a intenção de discutir os efeitos das ações do marketing organizacional sobre meio ambiente. O conceito de marketing verde pressupõe a ideia de que seja possível gerenciar o crescimento industrial através da diminuição de impactos ambientais negativos e a promoção de mudanças no composto de marketing afetem diretamente os hábitos dos consumidores em todos os níveis através da produção, do preço, da logística de distribuição e da divulgação desse composto, criando uma imagem diferenciada das empresas adeptas dessa prática (GONZAGA, 2005; VALDETARO, 2012).

8 A ISO International Organization for Standardization que em português traduz-se Organização Internacional para Padronização. É uma entidade que congrega os organismos certificadores de padronização/normalização para certificações de diversos tipos em mais de 170 países. A ISO foi fundada em fevereiro de 1947, em Genebra, na Suíça e aprova normas internacionais em todos os campos técnicos. Uma das suas normas mais famosas é a de garantia da qualidade série 9000 . No ano de 1993, a ISO reuniu diversos profissionais e criou um comitê, intitulado Comitê Técnico TC 207 que teria como objetivo desenvolver normas (série 14000) que pudessem garantir a qualidade ambiental integrada aos Sistemas de Gestão de qualquer tipo de organização. A certificação nas normas ISO série 14000 compatibilizam a incorporação da Gestão Ambiental à Gestão pela Qualidade Total nas empresas (AMARAL, A.C. et al, 2011). No Brasil a ABNT - Associação Brasileiras de Normas Técnicas constitui-se como um dos principais organismos certificadores de normas de garantia da qualidade, incluindo a norma ISO série 14000 (http://www.abnt.org.br/). Para aprofundar ainda mais a temática sugerimos a visita ao site da ISO: http://www.iso.org/iso/home.html.

9 Jonas (2007) e suas teorias apresenta a possibilidade da existência de um apocalipse gradual decorrente do perigo crescente dos riscos do progresso técnico global e seu uso inadequado. Para ele o alcance da ética reduzia-se ao âmbito dos relacionamentos entre as pessoas no momento presente. Isso representaria uma ética antropocêntrica e voltada para a contemporaneidade. $\mathrm{O}$ avanço alcançado pelo ser humano através da tecnologia mudou drasticamente essa realidade, a natureza passou a ser objetivada, tratada como algo que pode ser passível de drásticas alterações em função das vontades do ser humano. Com isso, para esse autor, a relação homem-natureza (da qual ele faz parte) passa a ser uma relação de responsabilidade, pois ela se encontra sob seu poder. Esse poder é capaz de interferir no meio físico natural disponível para a convivência das gerações futuras. Isso nos conduz à reflexão de uma nova ética. A da responsabilidade, que escape do antropocentrismo e consiga abarcar toda a natureza, incluindo o próprio ser humano e sua responsabilidade para com as gerações futuras.
} 
contribuir para a dupla operação de utilização de matéria-prima renovável associada ao uso adequado às necessidades, tendo em vista as gerações futuras. Essa dimensão coaduna-se à dimensão Ecorregional ao buscar ações de prevenção ao consumo excessivo.

4. Ecotécnica: implica no desenvolvimento de tecnologias que objetivem a eficiência energética através de fontes limpas, mas que considerem as fragilidades dos ecossistemas na tomada de decisão quanto aos projetos geradores de impactos para as comunidades e para o meio natural. Essa dimensão considera a tecnologia como uma variável multidimensional no interior do planejamento ambiental. Para Sachs (2007), essa dimensão não apresenta a tecnologia como uma forma de mascarar os problemas ambientais. Nesse caso, há a proposição da técnica com um novo olhar, a partir de um modelo tecnológico-educacional inovador.

5. Educacional: essa dimensão realiza-se por meio da educação formal e não-formal e constitui-se como essencial ao conceito de ecodesenvolvimento, pois contribui para o movimento de melhoria qualitativa dos padrões de valores em relação ao posicionamento humano frente à natureza da qual faz parte.

Para Sachs (2007) para que possamos tornar o ecodesenvolvimento operacional é necessário que observemos as variáveis envolvidas no campo de visão da economia do desenvolvimento ${ }^{10}$, com o acréscimo da variável do meio ambiente, onde:

M: meio ambiente (enquanto meio físico-natural ou construído pelo ser humano);

S: sociedade (em geral, com todas as suas especificidades);

T: técnica (desenvolvimento tecnológico);

P: produtos (bens e serviços oferecidos às pessoas);

$\mathbf{R}$ : recursos naturais (sua compreensão refere-se à base material necessária à manutenção das necessidades humanas, embora a expressão tenha uma conotação negativa em diversos contextos. Tais recursos encontram-se presentes no meio ambiente natural).

Na perspectiva de Sachs (2007), o mérito de observarmos as relações entre tais variáveis reside no fato de que elas revelam questões que devem ser consideradas no processo de gestão do ambiente somadas às dimensões tradicionais do planejamento. Ressaltamos, ainda que, de acordo com o mesmo autor, as variáveis devem ser analisadas na perspectiva de perceber que:

- O padrão de consumo depende do nível e da distribuição da renda, além dos valores que dada sociedade possui para direcioná-la a esse padrão;

- A internalização dos custos socioambientais deve ser buscada pelas empresas por meio de mecanismos do Estado, pois tradicionalmente, nas economias capitalistas, as empresas internalizam os lucros e externalizam os custos;

- O controle da taxa de obsolescência e as tecnologias de produção mais limpas, associadas ao baixo consumo energético, podem ser alternativas importantes, pois são indicadores da internalização da dimensão ambiental. Assim sendo, é preciso compreender a forma de utilização e escolha das matrizes energéticas e demais recursos provenientes do meio ambiente natural;

- As diversas formas de ocupação territorial e os níveis de crescimento da população devem ser pensadas a partir do pressuposto que a pressão pelo consumo de determinados produtos agrícolas pode causar sérios problemas ambientais como, por exemplo, o aumento da taxa de desmatamento em função da pecuária ou de monoculturas de exportação.

Os que defendem a modernização ecológica como solução para a problemática ambiental parecem pensar que os problemas ambientais estão apenas ligados à produção de lixo, gases e sucata, na forma de poluição, deixando de lado as questões sociais associadas à problemática ambiental como, por exemplo, as construções de hidrelétricas que são fontes geradoras de energia limpa, mas que causam

Isso implica em, uma sociedade que, no presente, pense em alternativas estratégicas para permitir que o futuro igual, ou melhor, seja garantido às próximas gerações. Nisso consiste a ética da responsabilidade.

10 É possível afirmar que a economia do desenvolvimento lida com os aspetos económicos do processo de desenvolvimento, especialmente, dos países considerados menos ricos. Seus estudos estão orientados para a melhoria do potencial da sociedade, por exemplo, por meio da melhoria das condições de saúde, educação e trabalho. Nesse sentido opera com a finalidade de elaborar métodos que contribuam para a promoção de mudanças estruturais nos países. 
terríveis danos sociais às comunidades que dependem das terras que são alagadas (CARNEIRO, 2005) ou as grandes plantações de cana que produzem um biocombustível ambientalmente amigáveis, mas que proporcionam, além da questão do esgotamento do solo por conta da monocultura, a problemática da mão de obra escrava (FERNANDES; LOURENCO, 2010).

\section{CONSIDERAÇÕES FINAIS}

Concordamos com Sachs (2007) quando afirma que a problemática ambiental está colocada e não há como fugir de seu enfrentamento. A definição de desenvolvimento sustentável contida no Relatório Brundtland (WECD, 1987), embora tenha origens liberais e aponte para a promoção da conservação da natureza apenas como recurso ${ }^{11}$, teve seu mérito ao direcionar a discussão para a arena política possibilitando, entre os estudiosos, a oportunidade de realizar análises e críticas, inserindo o termo sustentável na corrida pela disputa dos sentidos. De uma maneira geral, esse relatório proporcionou a reflexão, em diversos níveis, sobre a questão ambiental, onde alguns países estabeleceram ou ajustaram suas legislações e/ou criaram organismos e ministérios para lidar com a problemática.

Tanto os críticos mais contundentes quanto os defensores da manutenção do capitalismo concordam que existe uma crise ambiental instaurada. A questão que se apresenta é de como lidar com a problemática sem cair no ceticismo ingênuo que propaga a irreversibilidade e o fim da humanidade ou na armadilha das soluções puramente tecnológicas que prometem ser capazes de promover o crescimento constante e necessário à manutenção do sistema capitalista, sem alterar sua lógica.

Embora tenhamos a convicção de que estamos distantes de encontrar solução para a questão da sustentabilidade socioambiental, acreditamos, com base em Sachs (2007), que a gestão ambiental comprometida com o planejamento público orientado para um ideal emancipador é capaz de contribuir para a construção de sociedades sustentáveis que proporcionem melhoria das condições de vida das suas populações.

Ainda que se trabalhe a ecoeficiência, a modernização ecológica, o desenvolvimento sustentável e a economia verde, essas técnicas, por si só, não apresentam soluções que gerem um tipo de desenvolvimento que consiga promover mudanças estruturais no sistema em termos de políticas públicas e de novas formas de compreender e lidar com a temática do crescimento econômico.

O que os estudiosos do metabolismo industrial sugerem é que por meio do conhecimento do sistema industrial, em seus pormenores, é possível gerenciar a produção para que os processos de fabricação (desde o projeto do produto, passando pela construção e localização das fábricas, até o descarte) sejam eficientes ao ponto de ocasionar um balanço entre o consumo de materiais (matéria prima proveniente da natureza) e a produção de poluentes. Embora seja adotada (mesmo tacitamente) por autores que trabalham a questão da gestão ambiental no âmbito organizacional, a ecoeficiência não consegue abranger o campo socioambiental, pois reduz os problemas ambientais ao seu aspecto físico-material, deixando de lado as questões sociais inerentes à crise ambiental vigente.

Tal análise não implica em rejeitar a utilização da tecnologia para solucionar a crise ambiental, pois acreditamos que as ecotécnicas podem e devem ser empregadas. O desenvolvimento de tecnologias que conduzam a eficiência energética através de fontes limpas e que considerem as fragilidades dos ecossistemas na tomada de decisão quanto aos projetos geradores de impactos para as comunidades e para o meio natural é pertinente. Nessa ótica, é preciso desenvolver tecnologias que operem conjuntamente com avanços em termos de participação social-democrática.

Nesse sentido, ao abordar a temática da tecnologia, a educação ambiental deve evitar as formas de pensamento parciais e fragmentadas que mascaram a gravidade da crise socioambiental instaurada no país e no mundo. Uma educação ambiental que se proponha a propagar e aplicar as ecotécnicas na prática pedagógica cotidiana deve valorizar a ideia da responsabilidade coletiva e considerar a tecnologia como uma variável multidimensional no interior da educação que desvela as contradições do sistema capitalista, assumindo-as a partir de um modelo tecnológico-educacional inovador.

11 Recurso nesse contexto apresenta o sentido de base material para expansão do capital. 


\section{REFERÊNCIAS}

ACSELRAD, H.; LEROY, J. Novas premissas da sustentabilidade democrática. Rio de Janeiro: FASE, 1999.

AMARAL, A.C. et al . Criando valor para o acionista através da certificação ISO 14000: Um estudo múltiplo de casos. Rev. Portuguesa e Brasileira de Gestão, Lisboa, v. 10, n. 1-2, jan. 2011 . Disponível em http:// www.scielo.gpeari.mctes.pt/scielo.php?script=sci_arttext\&pid=S1645-44642011000100005\&lng=pt\&nrm=iso. acesso em jan 2012.

AYRES, R.U; SIMONIS, U.E. Industrial metabolismo: theory and policy. In:

AYRES, R.U; SIMONIS, U.E (orgs.). Industrial metabolismo: restruturing for sustainable development. Tokyo: United Nation University Press, 1994.

CARNEIRO, E. J. Política Ambiental e a ideologia do desenvolvimento sustentável. In: ZHOURI, A.; KLEMENS, L.; PEREIRA, D. B. (org.). A insustentável leveza da política ambiental: desenvolvimento e conflitos socioambientais. Belo Horizonte: Autêntica, 2005.

CARVALHO, Isabel C. M. O ambiental como valor substitutivo: uma reflexão sobre a identidade da educação ambiental. In: SAUVÉ, L. et al. Textos escolhidos em educação ambiental: de uma América à outra. Montreal, Publications ERE-UQAM, 2002, Tomo I, p. 85-90.

DALY, Herman. Beyond Growth. San Francisco: Freeman, 1997.

DIAS, Geraldo freire. Educação Ambiental: Princípios e práticas. 9 ed. São Paulo: Gaia, 2004.

FERNANDES, M.P.R; LOURENCO, E.A.S. Exploração do trabalho no corte de cana: breves apontamentos do senhor de engenho à agroindústria canavieira do século XXI. In: SEMINARIO DE SAUDE DO TRABALHADOR DE FRANCA, 7., 2010, Franca. Proceedings online. Unesp Dispnível em : http://www. proceedings.scielo.br/scielo.php?script $=$ sci_arttext\&pid=MSC0000000112010000100027\&lng=en\&nrm $=$ abn . Acesso em abr 2011.

FREITAS, Mario. Educação para o desenvolvimento sustentável. UFSC - Perspectiva. Florianópolis, v. 22, n.2, p. 547-575, 2004.

GADOTTI, Moacir. Educar para a sustentabilidade - Uma contribuição à década da educação para o desenvolvimento sustentável. São Paulo: Editora e Livraria Instituto Paulo Freire, 2008.

GEORGESCU-ROEGEN, N. Energy and Economic Myths. New York: Permagon Press, 1976.

GEORGESCU-ROEGEN, Nicolas. The entropy law and the economic process. Cambridge: Harvard University Press. 1971.

GONZAGA, C. A. M. Marketing verde de produtos florestais: teoria e prática. Floresta, v. 35, n. 2, p. 353$368,2005$.

GUIMARÃES, Simone S. Moreira, TOMAZELLO, Maria G. Carneiro. A formação universitária para o ambiente: educação para a sustentabilidade. In: REUNIÃO ANUAL DA ANPED, 26. 2003, Poços de Calda. Anais eletrônicos. Poços de Calda. Ed. ANPED, 2003. Disponível em: http://www.amped.org.br/inicio.html . Acesso em: 20 nov de 2004.

KALLIS, G; KERSCHNER, C; MARTINEZ-ALIER, J. The economics of degrowth. In: Ecological Economics. Vol. 84, pp 172-180, dez. 2012. Disponível em: http://www.sciencedirect.com/science/journal/09218009/84. Acesso em: abril 2013. 
LAYRARGUES, Philippe Pomier. Sistemas de gerenciamento ambiental, tecnologia limpa e consumidor verde: a delicada relação empresa-meio ambiente no ecocapitalismo. Rev. adm. empres., São Paulo, v. 40, n. 2, June 2000 . Disponível em: http://www.scielo.br/scielo.php?script=sci_arttext\&pid=S0034-75902000000200009\&lng=en\&nrm=iso. Acesso em 05 Mai 2013.

LEFF, E. Epistemologia Ambiental. 3 ed. São Paulo: Cortez, 2002.

LEIS, Hector Ricardo. Ética ecológica: análise conceitual e histórica de sua evolução. In: LEIS, Hector Ricardo (org.). Reflexão cristã sobre o meio ambiente. São Paulo: Loyola, 1992. p. 51-76.

LITTLE, Paul E. Políticas ambientais no Brasil: análises, instrumentos e experiências. São Paulo: Peirópolis; DF: IIEB, 2003.

LOUREIRO, Carlos Frederico B. Trajetória e fundamentos da Educação Ambiental. São Paulo: Cortez, 2004.

MANFRINATO, Jair Wagner de Souza. Correlação entre gestão da tecnologia e gestão ambiental nas empresas. Prod., São Paulo, v. 15, n. 2, ago. 2005 . Disponível em <http://www.scielo.br/scielo.php?script=sci_ arttext\&pid=S0103-65132005000200006\&lng=pt\&nrm=iso>. acessos em 06 abr. 2013.

MARTÍNEZ-ALIER, J. O ecologismo dos pobres: conflitos ambientais e linguagem de valoração. São Paulo: Contexto, 2007.

MÉSZÁROS, I. A crise estrutural do capital. São Paulo: Boitempo, 2011 .

I. Para além do capital. São Paulo: Boitempo, 2011 .

MININI, N. A formação dos professores em educação ambiental. In: Textos sobre capacitação em educação ambiental. Oficina Panorama da Educação Ambiental, MEC-SEF-DPEF-Coordenação de Educação Ambiental. Brasília, 2000. p. 15-22.

RODRIGUES, Neidson. Educação: da formação humana à construção do sujeito ético. Educação \& Sociedade. Belo Horizonte, n.12, p.232-257, 2001.

SACHS, I. A revolução energética do século XXI. Estud. av., São Paulo, v. 21, n. 59, Abr. 2007b. Disponível em: http://www.scielo.br/scielo.php?script=sci_arttext\&pid=S010340142007000100004\&lng=en\&nrm= iso. Acesso em mai 2011.

SACHS, I. Revisiting development in twenty-first century. In: International Journal of political economy. v. 38, n. 3, pp. 5-21. Set. 2009. Disponível em: http://ideas.repec.org/a/mes/ijpoec/v38y2009i3p5-21.html. Acesso em: fev. 2013.

SACHS, I. Rumo à ecossocioeconomia - Teoria e prática do desenvolvimento. São Paulo: Cortez, 2007.

SAUVÉ, Lucie. Educação ambiental e Desenvolvimento Sustentável: uma análise complexa. Revista de Educação Pública. UFMT - v. 10, 1997. Disponível em: http://cgi.ufmt.br/revista . Acesso em: 12 jan 2004.

SILVA, José Carlos Teixeira da; SILVA, Marcos Schaaf Teixeira; SILVA, José Carlos Teixeira da; SILVA, Marcos Schaaf Teixeira; UNESCO. Carta de Belgrado. 1975. Disponível em: http://www.mma.gov.br/. Acessado em 29/07/2011.

VALDETARO, E.B. et al. Diagnóstico do marketing ambiental de bens e serviços do setor florestal. Pesquisa Florestal Brasileira. Brazilian Journal of Foresty Research. Colombo, v. 32, n. 70, p. 221-225, abr./mai. 2012 Disponível em: www.cnpf.embrapa.br/pfb/index.php/pfb/article/download. Acesso em: 4 abril, 2012. 
VEIGA, J.E. Desenvolvimento sustentável: o desfio do século XXI. Rio de Janeiro: Garamond, 2010.

WCED (World Commission on Environment and Development). Our Common Future. New York, Oxford University Press, 1987. 